sition from doctors to the Seebohm proposals if the intention had been to introduce them gradually and when there were enough qualified, trained, and experienced social workers available. Proponents of early reform might argue that that would have taken too long, and that the only realistic way of strengthening the social work services was to offer a professionally and financially rewarding career structure. That might be so, but it is an argument that probably would bring wry smiles to the lips of senior public health doctors who have had to fight hard over the years to establish their professional position in local government.

One of the disturbing inferences to be drawn from most of the advertisements for directors and deputies is the absence of a professional qualification as a firm requirement for the posts, and a recent letter in the Medical Officer ${ }^{4}$ makes this point succintly. Social workers in these new departments will carry a formidable professional responsibility with implications for both patients and doctors. Seebohm now being a fait accompli, in the interests of the community doctors will have to do their best to make the reorganization work. They would do so with more confidence if working with colleagues whose professional training was comparable to their own.

\section{Hepatitis in Dialysis Units}

The incidence of hepatitis in haemodialysis units continues to increase in spite of the awareness of the risk of infection to both staff and patients. The recent severe outbreak at the Edinburgh Royal Infirmary and the Nuffield Transplantation Unit at Western General Hospital, Edinburgh, with 11 deaths (including four members of the medical staff) and the closing of Guy's Hospital unit after 69 cases of hepatitis had occurred (including 32 staff) have resulted in the establishment of an advisory group to the Department of Health to investigate this problem. ${ }^{1}$

Since 1965 several reports have indicated that the disease is usually serum hepatitis, presumably introduced by blood transfusions and subsequently spread by the extracorporeal circulation used in haemodialysis. ${ }^{2}{ }^{3}$ European $^{4}$ and American ${ }^{5}$ surveys before routine testing for Australian antigen was introduced indicated that $10^{\circ}{ }_{0}$ of the patients and $3 \%$ of the staff became infected.

The discovery of Australian antigen and its association with "long incubation" serum hepatitis by B. S. Blumberg and his colleagues in $1968,{ }^{6}$ has helped us to understand the alarmingly high incidence of hepatitis in dialysis units. If the presence of Australian antigen is used as a diagnostic criterion for hepatitis as well as conventional liver function tests and clinical evidence, the incidence of hepatitis appears to be higher than previously reported. ${ }^{7}$ Furthermore, routine screening for Australian antigen offers some hope for the future control of serum hepatitis. Probably most patients on dialysis, as opposed to normal people, will remain antigen-positive indefinitely after infection with serum hepatitis; some are found to be antigenpositive without preceding clinical or biochemical evidence of liver disease. ${ }^{7} 8$ The explanation for this phenomenon is unknown, but has been attributed to the reduced immunological response in patients with uraemia.

Thus there are many hepatitis carriers among patients being treated with dialysis, and because this involves regular and repeated handling of their blood, contact with potentially infected blood by staff and other patients is inevitable. Renal transplantation does not alter the antigen content of the blood in such patients and some have been reported to have become antigen-positive after transplantation. ${ }^{9}$ Hence the treatment of chronic renal failure is producing an ever increasing number of carriers of serum hepatitis. And their treatment by dialysis and transplantation inevitably means that susceptible staff and other patients are being exposed to the risk of infection.

Ideally this problem could be solved by preventing the introduction of antigen-positive blood into non-infected dialysis units. This can now be done in two main ways. Firstly, screening all blood transfusions used in dialysis for the presence of antigen. This may become much easier now that a rapid screening technique is available. ${ }^{10}$ Secondly, by refusing to accept potential patients who are already antigenpositive, or transient patients from other units. Though desirable on other grounds, reducing the number of blood transfusions ${ }^{11}$ has not prevented hepatitis epidemics in units which have introduced such a policy.

In the units affected segregating the carriers in their own homes, using home dialysis, is the only realistic method of control. ${ }^{12}$ In addition, complete isolation dialysis units will be necessary in each region to cope with the problem of hospital dialysis of patients who are Australian-antigen positive. These should be geographically separate from the routine units, contain separate equipment, and ideally should be staffed by people who are immune to hepatitis associated with Australian antigen (in other words, staff who have recovered from serum hepatitis). It is unrealistic to have such facilities in every dialysis unit, and so units will have to transfer their patients who are positive for the Australian antigen to the regional isolation unit. Facilities for transplantation will also have to be available in the isolation units, as the risk of infection at the time of surgery and after operation cannot be underestimated.

Regular screening of patients and staff for the antigen will help to detect new cases and allow them to be isolated several weeks before there is biochemical or clinical evidence of hepatitis. There is no evidence that gamma globulin is effective against serum hepatitis. "Sensible" methods of controlling cross infection, such as using gloves when handling blood, are essential.

The increasing use of the Cimino fistula with repeated venepuncture in patients on dialysis may be partly responsible for the spread of infection, as more blood is spilt than when an arteriovenous shunt is used. Both the supply of dialysate

British Medical fournal, 1970, 4, 123.

2 Ringertz, O., and Nyström, B., Scandinavian fournal of Urology and Nephrology, 1967, 1, 192.

${ }^{3}$ Jones, P. O., Goldsmith, H. J., Wright, F. K., Roberts, C., and Watson D. C., Lancet, 1967, 1, 835.

Drukker, W., Haagsma-Schouten, W. A. G., Alberts, C., and Spoek, M. G., in Dialysis and Renal Transplantation: Proceedings of the 6th Conference of the European Dialysis and Transplant Association, ed D. N. S. Kerr, p. 99. London, Pitman Medical, 1969.

Forrest, J. N., Dismukes, W. E., and Bryna, J. A., Dialysis Associated Hepatitis; Results of a Co-operative Survey conducted for the Hepatitis Unit, Epidemiology Programme. National Communicable Disease Centre, Atlanta, Georgia. U.S.P.H.S. 1968.

Blumberg, B. S., Sutnick, A. I., and London, W. T., Bulletin of the Nev York Academy of Medicine, 1968, 44, 1566

London, W. T., DiFiglia, M., Sutnick, A. I., and Blumberg, B. S., Ner England fournal of Medicine, 1969, 281, 571 .

Turner, G. C., and White, G. B. B., Lancet, 1969, 2, 121.

Knight, A. H., Baillod, R. A., and Moorhead, J. F., Proceedings of the European Dialysis and Transplant Association, 1970, 7, in press.

Mallick, N. P., Cleator, G. M., Beswick, T. S. L., and Orr, W. McN. Lancet, 1970, 2, 856.

1 Shaldon, S., Postgraduate Medical fournal, 1966, 2, 669.

12 Shaldon, S., and Oakley, J. J., in Dialysis and Renal Transplantation Proceedings of the 4th Conference of the European Dialysis and Transplant Association, ed. D. N. S. Kerr, p. 24. Amsterdam, Excerpta Medica, 1968.

13 Blumberg, A., and Giger, K., Proceedings of the European Dialysis and Transplant Association, 1970, 7, in press. 
and the monitoring unit may harbour the virus if the components are contaminated by infected blood, and usually several patients are maintained by one machine regardless of the type of dialyser used. The argument that disposable dialysers would reduce the incidence of infection has not been borne out in fact. One of the largest outbreaks with over 80 cases occurred in Stockholm when disposable dialysers were in use. ${ }^{2}$ More recently, a higher incidence of antigen-positive patients has been reported from a unit using disposable dialysers compared with a unit using Kiil dialysers. ${ }^{13}$ Nevertheless, when the Kiil dialyser is used each patient should have his own dialyser.

Until effective immunization can be given to staff-which implies the isolation of the virus and the production of a vaccine-the high incidence of morbidity and mortality among staff working in renal units justifies serious consideration for industrial compensation awards to all those who have contracted hepatitis while working in dialysis units. Moreover, the introduction of "danger money" for staff working in th em should also be considered.

\section{Back to Smoke Pollution}

An enormous administrative miscalculation is behind the announcement made last week that Britain is to import charcoal briquettes from France to keep the home fires burning this winter. Mr. Eldon Griffiths, Under Secretary at the new Department of Environment, stated when he announced this plan that three plants to produce gas coke were also to be kept open though scheduled for closure. The whole muddle is giving an opportunity for political exchanges on which this is not the place to comment, but the result of it is that one of Britain's main contributions to European Conservation Year is to pour more smoke into an already polluted atmosphere than it did before. Nor will this backward step in hygiene be limited to the present year: Mr. Griffiths could have no more than "every hope" that the shortage will no longer exist in two years time.

The introduction of North Sea gas has led to the closure of plants where gas is produced from coal, with the result that much less coke is now available from them. Since the high cost of gas puts it beyond the reach of many families, and since their houses are in any case equipped to burn only solid fuel, they must go back to using coal or an expensive smokeless substitute. The result is that the Government has had to suspend the smoke-control areas in many parts of the country to enable people to keep warm. All this was foreseen long before North Sea gas entered British homes. Back in 1964 complaints about local shortages of coke were widespread, and the fact that "in future coke will become scarcer owing to the greater use by gas boards of oil refinery gas and

1 British Medical fournal, 1964, 1, 324

2 Committee on Air Pollution, Report. London, H.M.S.O., 1954

3 Pemberton, J., and Goldberg, C., British Medical fournal, 1954, 2, 567.

- Pattle, R. E., and Cullumbine, H., British Medical fournal, 1956, 2, 913.

S Fairbairn, A. S., and Reid, D. D., British fournal of Preventive and Social Medicine, 1958, 12, 94.

6 Stocks, P., British Medical fournal, 1959, 1, 14

Lawther, P. J., Martin, A. E., and Wilkins, E. T., Epidemiology of Air Pollution. World Health Organization, Geneva, 1962.

8 Committee of the Royal College of Physicians of London, Air Pollution and Health. London, Pitman, 1970

9 Colley, J. R. T., and Reid, D. D., British Medical fournal, 1970, 2, 213.

${ }^{10}$ Hawksworth, D. L., and Rose, F., Nature, 1970, 227, 145.

11 British Medical fournal, 1970, 3, 533. natural gas" was stated in these columns. ${ }^{1} \mathrm{~A}$ thorough inquiry ought to be made into the fiasco that now seems likely to increase the amount and severity of respiratory disease in the coming winters.

Evidence that air containing the products of combustion, especially from domestic fires, does cause serious harm to health was overwhelming in the London smog of December 1952 , which resulted in the death of some 4,000 people. The Beaver report ${ }^{2}$ and the legislation for cleaner air that stemmed from it were a direct consequence of that disaster. Since then many investigations have confirmed and added to previous studies linking polluted air with respiratory disease, ${ }^{3-8}$ even among children. ${ }^{9}$ But, though cities are cleaner and people probably healthier when heavy smoke from bituminous coal ceases to fill the air in the neighbourhood of houses, the precise substances in the atmosphere that statistical studies have shown to be harmful to health need further elucidation. Another question is whether the burning of smokeless fuels removes from the air heavy smoke that brings down noxious substances in cities but enhances their dispersal over a wider area. If that is so, the smoke control orders, which should be reimposed as soon as is practicable, are only a step towards providing a pure atmosphere.

Direct measurement of some products of combustion in the atmosphere by sampling gauges, mostly near urban and industrial areas, has in recent years been supplemented by study of the biclogical effects of polluted air. Much the most sensitive organisms appear to be the lichens, and the lethal effects of atmospheric pollution on them are well documented in Britain and other countries. Recently D. L. Hawksworth and $\mathrm{F}$. Rose $\mathrm{R}^{10}$ have carried the study a stage further by introducing a scale of air pollution based on the communities of lichens growing on tree trunks. Further work is needed to confirm their correlation between pollution and lichen communities and to show what general biological significance it may have, but it has the merit of not being restricted to the problems of "black" smoke or to the few areas where expensive sampling equipment can be installed. Obtaining an atmosphere free of toxic compounds as well as carbon particles is the real goal, and the international network being set up by the World Health Organization with that among its aims is welcome. ${ }^{11}$ Meanwhile many people's health would dramatically improve if they kept the atmosphere in their lungs free of tobacco smoke.

\section{Genital Herpes and Cervical Cancer}

Evidence has been growing that sexual intercourse bears some relationship to carcinoma-in-situ and invasive carcinoma of the cervix. A correlation has been reported for both diseases with age at first marriage, age at first pregnancy, and number of pregnancies." Study of a "micro-epidemic" in a single housing estate in the U.S.A. showed that each of the 10 patients had had several different sexual partners. ${ }^{2}$

A suspicion that the venereal factor might be a herpesvirus arose when W. R. Dowdle and colleagues ${ }^{3}$ found that Herpesvirus hominis isolates from a variety of sites in the body could be divided into two distinct antigenic types-type 1 (HSV-1) from sites other than genital and type 2 (HSV-2) only from the adult genital tract. HSV-2 could be derived 